\title{
Multi-organ failure secondary to an aortocaval fistula-when should it be suspected?
}

\author{
Samar Medani, Frank Walker, Sean Leavey \\ Department of Nephrology, University Hospital Waterford, Waterford, Ireland
}

Correspondence: Samar Medani. Address: University Hospital Waterford, Ireland. Email: smedani@doctors.org.uk

Received: August 25, 2015

DOI : $10.5430 /$ crim.v2n4p72

Accepted: October 20, 2015

URL: http://dx.doi.org/10.5430/crim.v2n4p72
Online Published: October 27, 2015

\begin{abstract}
Spontaneous aortocaval fistula (ACF) is a rare, life threatening complication of abdominal aortic aneurysms (AAA) which is seldom suspected clinically. We report a case of progressive multi-organ failure secondary to an ACF wherein a delayed diagnosis was followed by a successful outcome. A 67-year-old man presented with dyspnoea on exertion, cough, and night sweats for three weeks. Initial investigations showed type 1 respiratory failure and mild renal impairment. He was treated for a suspected respiratory tract infection and fluid overload but antibiotic and diuretic therapies were ineffective. Within the following 36 hours he developed progressive azotemia and acute liver failure. He had physical signs of predominantly right-sided heart failure with preserved left ventricular systolic function on echocardiogram. Abdominal ultrasound and a non-contrast computed tomography (CT) revealed mild hepatomegaly, a $10 \mathrm{~cm}$ AAA with no evident leak and unremarkable kidneys. Oliguria and metabolic acidosis ensued with rapid deterioration of renal function and hypotension necessitating continuous veno-venous hemofiltration with inotropic support. Hepatic and renal function improved within a week of intensive care therapy but signs of volume overload persisted. A contrast abdominal CT demonstrated an ACF, which was successfully managed by endovascular stent-grafting. This case highlights the importance of being alert to the haemodynamic consequences of aortocaval rupture particularly in the presence of a large AAA in a patient presenting with unexplained organ failure and hyperkinetic shock. Optimisation of supportive care impacts favourably on the perioperative course and overall prognosis of this rare condition.
\end{abstract}

\section{Keywords}

Aorto-caval fistula, Multi-organ failure, High output cardiac failure, Endovascular repair

\section{Introduction}

Spontaneous aortocaval fistula (ACF) is a rare life threatening complication of abdominal aortic aneurysms (AAA). Diagnosis is often delayed, particularly with atypical presentations ${ }^{[1]}$. Although renal insufficiency is not an uncommon associated manifestation, severe acute renal failure (ARF) secondary to an ACF necessitating renal replacement therapy preoperatively has seldom been reported ${ }^{[2-5]}$. ACF should be suspected in the presence of a large AAA in a patient presenting with hyperdynamic shock and multi-organ failure. A preoperative diagnosis and supportive management of ACF have been associated with improved postoperative outcomes in the literature ${ }^{[6]}$. 


\section{Case presentation}

\subsection{History and physical findings}

A 67-year-old man was referred by his general practitioner with a three week history of exertional dyspnoea, cough productive of white sputum, and night sweats that responded poorly to oral antibiotic therapy. He had a background of type 2 diabetes and coronary artery stenting. He was married, an ex-smoker and drank alcohol on social occasions. His regular medications were aspirin, metoprolol, metformin, lisinopril and pravastatin. He appeared well, his heart rate was 122 beats/minute and other vital signs were normal. Heart sounds were normal and there was reduced air entry at the lung bases with crepitations. Abdomen was soft and non-tender with no palpable organs.

\subsection{Diagnostic work-up, hospital course \& initial management}

Chest X-ray (CXR) showed bilateral pleural effusions and fluid in the right horizontal fissure. Electrocardiogram (ECG) was unremarkable except for evidence of an old inferior infarction. There were no dramatic derangements in the initial laboratory tests (see Table 1). Mild anaemia was noted as well as a raised creatinine of $135 \mu \mathrm{mol} / \mathrm{L}$. Baseline creatinine was $100 \mu \mathrm{mol}$ four months prior to admission. Arterial blood gas (ABG) analysis showed mild hypoxia and a mild compensated metabolic acidosis. An intravenous antibiotic (co-amoxiclav) and diuretic therapy were commenced and metformin was held. On day 3 of hospitalisation, marked derangement of liver function tests was noted in a predominantly hepatocellular pattern. The patient's dysnoea and cough persisted. On examination his BP was stable at 110/60, he was tachypnoeac with $\mathrm{SpO}_{2} 97 \%$ on room air (RA), and he had a low grade fever with a temperature between $37.8^{\circ} \mathrm{C}$ and $38.0^{\circ} \mathrm{C}$. His jugular venous pressure was raised and a few crepitations were heard over the right lung base. He had mild pedal oedema. Repeat laboratory blood tests were as shown in Table 1 . There was evidence of severe acute renal and hepatic injury. An echocardiogram showed a non-dilated left ventricle with an ejection fraction of $44 \%-55 \%$, and a mildly dilated right heart with good function. There were no ECG changes or biochemical evidence of an acute coronary syndrome. On repeat CXR there was upper lobe venous diversion with evidence of progressive interstitial oedema and a right base consolidation. Abdominal ultrasound (US) showed a $10 \mathrm{~cm}$ AAA with no evidence of bleeding into the intraperitoneal or retroperitoneal spaces, a slightly enlarged hyperechoic liver with no intra-hepatic biliary duct dilatation, a contracted gallbladder and normal common bile duct. The pancreas, spleen and kidneys were unremarkable. Over the next few hours urine output dropped to $<15 \mathrm{ml} /$ hour, blood pressure dropped to 95/51, oxygen saturations to 95\% on RA; repeat ABG showed worsening hypoxia and metabolic acidosis. D-dimer was markedly raised at 2,630. Subcutaneous low molecular weight heparin (LMWH) was commenced because of suspicion of pulmonary embolism (PE) and co-amoxiclav was replaced with a more broad-spectrum antimicrobial regimen. Due to worsening of metabolic acidosis (pH 7.28), hyperkalemia and refractory volume overload with oliguria the patient was transferred to the intensive care unit (ICU) for continuous veno-venous hemodiafiltration with inotropic support. He did not require ventilatory support. Central venous pressure was $26 \mathrm{~cm} \mathrm{H}_{2} \mathrm{O}$. A volume of 4.5 litres of fluid was removed in 72 hours. Within a week of ICU admission, there was dramatic improvement in hepatic and renal function but ongoing signs of fluid retention. Further history taking disclosed an episode of lower chest and upper abdominal pain associated with hypotension one week prior to admission when the patient was managed in the community. A non-contrast abdominal CT during the fourth week of admission showed stable appearance of the AAA compared to the earlier ultrasonographic findings. With persistence of diuretic refractory volume overload a week later, a contrast CT was obtained which demonstrated an infra-renal $11.5 \mathrm{~cm}$ AAA with focal ulceration into the inferior vena cava (IVC) associated with caval thrombosis at the indentation site (see Figure 1). There was bilateral lung consolidation and enlarging pleural effusions in a pattern consistent with cardiac failure. The unifying diagnosis of an ACF with associated high-output cardiac failure was made and the patient was referred for urgent surgical intervention.

Table 1 shows the patient's laboratory data at different time points throughout the admission and on follow up 4 weeks post surgery. Renal and hepatic function recovered to a normal baseline. CT imaging of the abdomen with contrast is shown in Figure 1 demonstrating the large abdominal aortic aneurysm and aortocaval fistula. 
Figure 1. Computed tomography of abdomen with contrast showing large abdominal aortic aneurysm (AAA) and infra-renal aortocaval fistula (arrow)

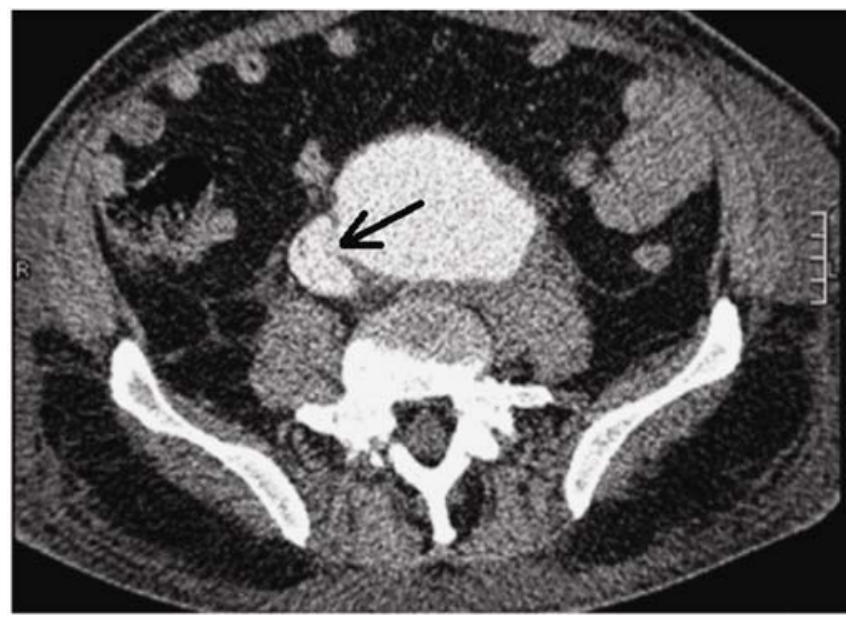

Table 1. Laboratory data of patient with aortocaval fistula at different stages during treatment course

\begin{tabular}{|c|c|c|c|c|c|c|c|c|c|}
\hline $\begin{array}{l}\text { Laboratory results } \\
\text { (Reference ranges) }\end{array}$ & Day $1 *$ & Day 2 & Day 3 & $\begin{array}{l}\text { Day } 4 \\
\text { (pre-ICU) }\end{array}$ & $\begin{array}{l}\text { Day } 4 \\
\text { (ICU-On } \\
\text { CRRT) }\end{array}$ & Day 5 & $\begin{array}{l}\text { Day } 10 \\
\text { (off CRRT) }\end{array}$ & $\begin{array}{l}\text { Day } 28 \\
\text { (one week } \\
\text { preop) }\end{array}$ & $\begin{array}{l}4 \text { weeks } \\
\text { postop }\end{array}$ \\
\hline $\begin{array}{l}\mathrm{Hb}(\mathrm{g} / \mathrm{dl}) \\
(13.0-18.5)\end{array}$ & 11 & - & 11.3 & 9.9 & 10.8 & 10.7 & 9.8 & 10.7 & - \\
\hline $\begin{array}{l}\text { WBC }\left(\times 10^{9} / \mathrm{L}\right) \\
(4.0-11.0)\end{array}$ & 6.0 & - & 7.3 & 14.2 & 16.3 & 11.8 & 6.5 & 10.0 & - \\
\hline $\begin{array}{l}\text { Urea }(\mathrm{mmol} / \mathrm{L}) \\
(2.1-6.4)\end{array}$ & 12.2 & 13.9 & 21.9 & 25.2 & 20.0 & 13.5 & 9.3 & 31.0 & 5.6 \\
\hline $\begin{array}{l}\text { Creatinine }(\mu \mathrm{mol} / \mathrm{L}) \\
(50-115)\end{array}$ & 135 & 194 & 283 & 426 & 361 & 308 & 188 & 175 & 100 \\
\hline $\begin{array}{l}\mathrm{Na}(\mathrm{mmol} / \mathrm{L}) \\
(132-146)\end{array}$ & 139 & 138 & 136 & 135 & 133 & 134 & 135 & 127 & 139 \\
\hline $\begin{array}{l}\mathrm{K}(\mathrm{mmol} / \mathrm{L}) \\
(3.5-5.0)\end{array}$ & 5.0 & 5.2 & 5.9 & 7.5 & 4.4 & 4.3 & 3.6 & 4.2 & 3.5 \\
\hline $\begin{array}{l}\text { Albumin(g/L) } \\
(35-50)\end{array}$ & - & 32 & 31 & - & 32 & 30 & - & 20 & 26 \\
\hline INR & 1.1 & - & 1.5 & 3.0 & 3.5 & 5.3 & 2.7 & 2.1 & - \\
\hline $\begin{array}{l}\text { Bilirubin }(\mu \mathrm{mol} / \mathrm{L}) \\
(<17)\end{array}$ & 20 & 33 & 53 & 79 & 88 & 91 & 128 & 74 & 23 \\
\hline $\begin{array}{l}\text { ALP (IU/L) } \\
(42-121)\end{array}$ & 95 & 94 & 118 & 147 & 165 & 172 & 168 & 158 & 80 \\
\hline $\begin{array}{l}\text { AST (IU/L) } \\
(15-41)\end{array}$ & 55 & 72 & 2,861 & 6,120 & 10,725 & 6,832 & 905 & 56 & 25 \\
\hline $\begin{array}{l}\text { ALT (IU/L) } \\
(17-63)\end{array}$ & 120 & 116 & 1,663 & 3655 & 4,865 & 4,093 & 1,653 & 38 & 24 \\
\hline $\begin{array}{l}\text { CPK (U/L) } \\
(38-174)\end{array}$ & 110 & - & - & - & - & - & - & - & - \\
\hline D Dimer $(\mu \mathrm{g} / \mathrm{L})$ & 632 & & 2,630 & & & & & & \\
\hline
\end{tabular}

*Day 1 corresponds to the date of admission to hospital. CRRT = continuous renal replacement therapy; Preop = preoperatively; Postop = postoperatively; WBC = white blood cells; $\mathrm{Na}=$ sodium; $\mathrm{K}$ = potassium; INR = international normalised ratio; ALP = alkaline phosphatase; AST = aspartate aminotransferase; ALT = alanine aminotransferase; $\mathrm{CPK}=$ creatine phosphokinase. 


\subsection{Differential diagnosis}

The patient was initially treated for a suspected community acquired pneumonia and congestive heart failure on a background of atherosclerotic cardiovascular disease. The presentation was compounded by rapidly progressive hepatic and renal failure with severe metabolic acidosis out of proportion to the haemodynamic instability. Sepsis was considered and antibiotic therapy was broadened to cover atypical bacterial, viral and fungal pneumonia. Blood cultures taken on admission and 48 hours later were negative. Only commensal organisms were grown on sputum culture. Serological testing for atypical pneumonia organisms including leptospiposis and Q fever was negative as was urine testing for legionella and pneumococcal antigens. ARF is not a typical feature of acute $\mathrm{Q}$ fever although the association has been rarely reported ${ }^{[7,8]}$. The predominantly hepatocellular pattern of liver injury was not consistent with the cholestatic picture characteristic of icteric leptospirosis (Weil's disease) ${ }^{[9]}$. An idiosyncratic reaction to co-amoxiclav resulting in hepato-renal failure was likewise considered to be unlikely with the observed pattern of transaminitis, the drug was however discontinued. There was no rash or oesinophilia. Serology for hepatitis A, B, C as well as acute cytomegalovirus (CMV) and Epstein-Barr virus (EBV) infections was negative. Rhabdomyolysis was excluded by a minimally elevated creatine phosphokinase (CPK). The markedly elevated D-dimer level with a prominence of respiratory symptoms, hypoxemia and predominantly right sided heart failure raised a clinical suspicion of PE; However, echocardiographic findings were not consistent with a haemodynamically or clinically relevant PE. There was no significant elevation of right ventricular systolic pressure or tricuspid regurgitation. As the patient had no abdominal pain at presentation, attention was diverted from a more focused abdominal examination to a presumed primary cardio-respiratory pathology but the marked transaminitis prompted an urgent abdominal US which demonstrated the aneurysm. Finally, the possibility of a contained aneurysmal leak and secondary compression or thrombosis of the IVC was considered and a contrast enhanced CT was obtained leading to the diagnosis of the ACF. The salient features pointing to the diagnosis were the marked diuretic resistant hyperdynamic overload status, with prominent signs of central venous congestion and preserved biventricular function.

\subsection{Definitive treatment \& outcome}

The patient underwent successful endovascular repair and his postoperative recovery was uneventful. He regained independant renal function preoperatively and his creatinine stabilised postoperatively at its previous baseline of around $100 \mu \mathrm{mol} / \mathrm{L}$. Six years following surgery, he remains asymptomatic with no evidence of endoleak or recurrence of ACF.

\section{Discussion}

Spontaneous aortocaval fistula formation is reported to occur in averagely $4 \%$ of ruptured abdominal aortic aneurysms ${ }^{[5,6,10-13]}$. The condition was first described in 1831 by Syme ${ }^{[14]}$. Over the following one and a half century approximately, an average of one case per year worldwide had been reported in the English literature (159 cases in 160 years) ${ }^{[15]}$. There is a striking male predominance with presentation typically happening after middle age, although the index case was a young man with syphilic aortitis ${ }^{[14]}$. Traditionally diagnosis was made by conventional angiography until the 1980s. Subsequently, contrast enhanced CT has become the standard imaging modality of choice ${ }^{[16,17]}$. A classical triad of abdominal or lower back pain, a pulsatile abdominal mass and a machinary abdominal murmur often with findings suggestive of high output congestive cardiac failure (CCF) have been described in typical presentations of ACF ${ }^{[18,19]}$. Mural thrombus or compression of the IVC by the aortic aneurysm may be associated with restriction of venous return, accentuation of regional venous hypertension and attenuation of the fistula bruit ${ }^{[6,19]}$. In many patients however, some of these symptoms and signs are absent or missed due to other less typical but clinically prominent and distracting features such as haematuria due to venous hypertension, severe renal and/or hepatic injury due to the haemodynamic alterations, syncope, transient ischemic attack, angina, palpitations, cough, or constitutional symptoms such as lethargy, low grade fever and sweating. Thus, in the absence of abdominal or back pain, a diagnosis of ACF may be easily overlooked and a palpable AAA or an abdominal bruit may be missed. Likewise, features of CCF may not be prominent ${ }^{[6]}$. Oliguric acute kidney injury may occur without any significant drop in systolic blood pressure ${ }^{[13,17]}$. Proposed mechanisms of renal injury include reduced total peripheral resistance and renal venous hypertension leading to reduced renal arterial perfusion 
pressure ${ }^{[11]}$. A compensatory increase in the cardiac output helps maintain systolic blood pressure in patients with preserved cardiac function. Severe acute ischaemic hepatitis has been reported in association with $\operatorname{ACF}^{[3,20]}$.

The goals of management are haemodynamic stabilisation, surgical correction with control of bleeding and prevention of venous thromboembolism (VTE). A preoperative diagnosis allows better haemostatic control and specific care to avoid paradoxical embolism due to dislodged atheromatous debris. Operative mortality is approximately $30 \%$ with open surgery due to complications such as haemorrhage, myocardial infarction, coagulopathy and thromboembolism ${ }^{[11,21]}$. The role of rapidly evolving endovascular modalities has been well documented in the treatment of AAA. The use of these newer techniques in ACF repair has gained favour in more recent years and in selected cases appears to be associated with high success rates although the rarity of the condition and reporting bias for both strategies limit any conclusions from current data regarding a survival advantage ${ }^{[21]}$. Notwithstanding the limitation of data, a recent systematic review of case reports of endovascular repair of major abdominal arteriovenous fistulas presented a $94 \%$ technical success rate and $0 \%$ and $10 \%$ intra-operative and 90-day mortality respectively ${ }^{[22]}$.

Anticoagulation is potentially harmful with large AAAs. A positive D-dimer lacks specificity for diagnosing VTE, and should be interpreted with particular caution in this setting. ACF may present predominantly as in our case with respiratory symptoms, type 1 respiratory failure and signs of central venous congestion, suggesting an incorrect diagnosis of PE on clinical grounds. On the other hand, ACF may at times be complicated by paradoxical PE or IVC thrombosis with secondary PE ${ }^{[23,24]}$. Although renal impairment may be a concern; contrast imaging is warranted to diagnose or rule out concurrent PE if clinically suspected in such a situation as placement of an IVC filter may be required.

Despite a delay in diagnosis in this case owing to the atypical and insidious presentation, prompt instigation of short term critical care support and a later preoperative diagnosis were associated with a good surgical outcome. It is postulated that with timely interim supportive measures compensatory mechanisms and physiologic adaptations to the acute circulatory changes were allowed to take place, stabilising the patient before surgical intervention.

\section{Conclusion}

(1) Contained rupture of an AAA with ACF formation can masquerade as diuretic resistant high output CCF with secondary multi-organ dysfunction.

(2) Abdominal and/or back pain is not universal and clinical signs of an AAA may be overlooked. Signs of organ hypoperfusion, lower body venous hypertension, and rarely, thromboembolism may predominate making the clinical presentation of ACF widely variable. Lack of clinical suspicion and awareness of the condition contribute to diagnostic delays and poorer outcomes.

(3) Non contrast CT imaging can detect extra-peritoneal haemorrhage but cannot exclude an intramural dissection or an ACF.

(4) PE occasionally complicates an ACF due to IVC thrombosis or paradoxical embolism but may frequently be suspected when ACF presents with respiratory symptoms, hypoxemia and signs of right ventricular failure. An elevated D Dimer is expected with a ruptured AAA and has a low positive predictive value for PE. Empiric anticoagulation while delaying contrast exposure in this setting should be avoided.

(5) Endovascular stent grafting offers a promising, increasingly employed technique in the management of ACF with excellent short and intermediate term outcomes.

\section{References}

[1] Bhogal RH, Nayeemuddin M, Wilson S. An Unusual Presentation of Aorto-caval Fistula. Internet Journal of Anesthesiology. 2007; $14(2)$. 
[2] Takkar C, Choi L, Mastouri N, et al. Aortocaval Fistula: A Rare Cause of Venous Hypertension and Acute Renal Failure. Case reports in surgery. 2012. http://dx.doi.org/10.1155/2012/487079

[3] Kanbay M, Gur G, Boyvat F, et al. Spontaneous aortocaval fistula presenting with acute liver and renal failure: a case report. Turk J Gastroenterol. 2004; 15(3): 169-172. PMid:15492916

[4] Hervas V, Esteban JM, García-Ferrer L. Aortocaval fistula presenting with hematuria and renal failure. EJVES Extra. 2007; 14(3): 33. http://dx.doi.org/10.1016/j.ejvsextra.2007.05.003

[5] Albalate M, Octavio JG, Llobregat R, et al. Acute renal failure due to aortocaval fistula. Nephrology Dialysis Transplantation. 1998; 13(5): 1268-1270. http://dx.doi.org/10.1093/ndt/13.5.1268

[6] Brewster DC, Ottinger LW, Darling RC. Hematuria as a sign of aorto-caval fistula. Annals of surgery. $1977 ; 186(6)$ : 766. PMid:603281 http://dx.doi.org/10.1097/00000658-197712000-00020

[7] Morovic M, Dzelalija B, Novakovic S, et al. Acute renal failure as the main complication of acute infection with Coxiella burnetii. Nephron. 1993; 64: 335. PMid:8321379 http://dx.doi.org/10.1159/000187348

[8] Korman TM, Spelman DW, Perry GJ, et al. Acute glomerulonephritis associated with acute Q fever: case report and review of the renal complications of Coxiellaburnetii infection. Clin Infect Dis. 1998; 26: 359-364. PMid:9502456 http://dx.doi.org/10.1086/516308

[9] Paul N Levett. Leptospirosis. Clin. Microbiol. Rev. 2001; 14(2): 296-326. PMid:11292640 http://dx.doi.org/10.1128/CMR.14.2.296-326.2001

[10] Woolley DS, Spence RK. Aortocaval fistula treated by aortic exclusion. Journal of vascular surgery. 1995: 22(5): 639-642. http://dx.doi.org/10.1016/S0741-5214(95)70053-6

[11] Rajmohan B. Spontaneous aortocaval fistula. Journal of postgraduate medicine. 2002; 48(3): 203. PMid:12432197

[12] Brunkwall J, Länne T, Bergentz SE. Acute renal impairment due to a primary aortocaval fistula is normalised after a successful operation. European journal of vascular and endovascular surgery. 1999; 17(3): 191-196. PMid:10092889 http://dx.doi.org/10.1053/ejvs.1998.0688

[13] Duffy JP, Gardham JR. Spontaneous aortocaval fistula-preoperative diagnosis and management. Postgraduate medical journal. 1989; 65(764): 397-399. PMid:2608582 http://dx.doi.org/10.1136/pgmj.65.764.397

[14] Syme J. Case of spontaneous varicose aneurysm. Med Surg J. 1831; 36: 104-5.

[15] Keith DC, Ronald PS, Dominic AD. Unusual aspects of aortovenous fistulas associated with ruptured abdominal aortic aneurysms. Journal of vascular surgery. 1990; 12(5): 586-590. http://dx.doi.org/10.1016/0741-5214(90)90016-4

[16] Venketraman S, Kotnis N, DeNunzio M, et al. The use of Computed Tomography in the diagnosis and management of aorto-caval fistula. EJVES Extra. 2004; 8(2): 31-33. http://dx.doi.org/10.1016/j.ejvsextra.2004.06.001

[17] Tonolini M, Ippolito S, Rigiroli F. Images in medicine: Spontaneous aortocaval fistula complicating abdominal aortic aneurysm. Journal of Emergencies, Trauma, and Shock. 2014; 7(2): 129. PMid:24812461 http://dx.doi.org/10.4103/0974-2700.130888

[18] Cortis BS, Jablokow VR, Shah AN, et al. Spontaneous rupture of an abdominal aortic aneurysm into the inferior vena cava: a case report and review of the literature. The Mount Sinai journal of medicine, New York. 1972; 39(6): 566. PMid:4539195

[19] Nennhaus HP, Javid H. The distinct syndrome of spontaneous abdominal aortocaval fistula. Am J Med. 1968; 44 : 464-473. http://dx.doi.org/10.1016/0002-9343(68)90117-4

[20] Sobrinho G, Ferreira ME, Albino JP, et al. Acute ischemic hepatitis in aortocaval fistula. European journal of vascular and endovascular surgery. 2005; 29(3): 239-243. PMid:15694794 http://dx.doi.org/10.1016/j.ejvs.2004.12.006

[21] Brightwell RE, Pegna V, Boyne N. Aortocaval fistula: current management strategies. ANZ journal of surgery. 2013; 83(1-2): 31-35. PMid:23072669 http://dx.doi.org/10.1111/j.1445-2197.2012.06294.x

[22] Nakad G, AbiChedid G, Osman R. Endovascular treatment of major abdominal arteriovenous fistulas: a systematic review. Vasc. Endovasc. Surg. 2014; 48(5-6): 388-395. PMid:24973241 http://dx.doi.org/10.1177/1538574414540485

[23] De Rango P, Parlani G, Cieri E, et al. Paradoxical pulmonary embolism with spontaneous aortocaval fistula. Annals of vascular surgery. 2012; 26(5): 739-746. PMid:22197523 http://dx.doi.org/10.1016/j.avsg.2011.06.011

[24] Tsolakis JA, Papadoulas S, Kakkos SK, et al. Aortocaval fistula in ruptured aneurysms. European journal of vascular and endovascular surgery. 1999; 17(5): 390-393. PMid:10329521 http://dx.doi.org/10.1053/ejvs.1998.0777 